\title{
Inflammatory infiltration, fibrosis, necrosis and mucinous content in relation to clinicopathological and molecular factors in rectal cancers with or without preoperative radiotherapy
}

\author{
ANNICA KNUTSEN, GUNNAR ADELL and XIAO-FENG SUN \\ Institute of Biomedicine and Surgery, Department of Oncology, Linköping University, Linköping, Sweden
}

Received February 7, 2006; Accepted April 7, 2006

\begin{abstract}
The association between inflammatory infiltration, fibrosis, necrosis and mucinous content in rectal cancers, and their relationship to preoperative radiotherapy (RT) clinicopathological and biological factors (p53, apoptosis and Cox-2) is not fully characterised. We analysed these histopathological parameters and their relationships in rectal cancer patients who participated in a clinical trial of preoperative RT. One hundred and forty-eight preoperative biopsies and 153 surgically resected tumours were examined. Of the surgical specimens, 81 had surgery alone and 72 received RT before surgery. A higher grade of inflammatory infiltration was related to favourable survival in the whole group of patients $(\mathrm{p}=0.004$, for multivariate analysis $\mathrm{p}=0.01$ ) as well as in the subgroups of patients with $(\mathrm{p}=0.04)$ or without RT ( $\mathrm{p}=0.01)$. After RT, tumours showed a decreased infiltration $(p=0.0003)$ and increased necrosis $(p=0.006)$, strong necrosis was related to favourable survival $(\mathrm{p}=0.046)$. Necrosis $(p=0.054)$ and fibrosis $(p=0.06)$ tended to be increased in p53-negative tumours after RT. Inflammatory infiltration was a strong prognostic factor in rectal cancer patients, regardless of RT. RT tended to induce necrosis and fibrosis in p53-negative tumours.
\end{abstract}

\section{Introduction}

The infiltration of inflammatory cells in tumour tissue is considered an important factor of the host response, and is related to improved survival in colorectal cancer patients (1-3). The antitumour effect of inflammatory infiltration is suggested to be mediated by the activation of B-cells, cytotoxic T cells, NK cells, macrophages and complement, which kills tumour cells by lysis (4). Fibrosis consists of dense

Correspondence to: Professor Xiao-Feng Sun, Institute of Biomedicine and Surgery, Department of Oncology, Linköping University, S-58185 Linköping, Sweden

E-mail: xiasu@ibk.liu.se

Key words: inflammatory infiltration, necrosis, prognosis, radiotherapy, rectal cancer connective tissue produced by fibroblasts, and is proposed to have a growth limiting effect on tumour cells and is thus related to improved survival in colorectal cancer patients $(5,6)$. Necrosis and mucinous content are histopathological factors related to a poor clinical outcome in colorectal cancer patients $(3,7,8)$. Necrosis is initiated by irreversible exogenous injury that leads to denaturation of proteins and enzymatic digestion of the cell, while cells in mucinous tumours have increased mucus secretion, high apoptotic activity and low proliferation during tumour development (7). p53 and Cox-2 are important proteins in tumour development. Loss of p53 function leads to interference with DNA-damage repair, cell proliferation, genomic stability and programmed cell death while Cox-2 is a key enzyme in the inflammatory process that catalyses the formation of prostaglandins.

Variant histopathological parameters have been studied in patients with rectal cancer $(1,2,5,9)$. Shia et al (2) investigated stromal response, type of inflammatory infiltrate, necrosis and mucinous content in rectal cancer patients treated with chemoradiotherapy (RT), and others have examined inflammatory infiltrate and fibrosis in relation to survival in rectal cancer patients with or without RT $(1,5)$. Very few studies have investigated the associations between these histopathological parameters as well as their clinicopathological and biological significance in rectal cancer patients. The aim of this study was to investigate the association between inflammatory infiltration, fibrosis, necrosis and mucinous content, and their relationship to RT, clinicopathological variables, and biological factors including p53, apoptosis and Cox-2 in rectal cancer patients who participated in a clinical trial of preoperative RT.

\section{Patients and methods}

Patients. The present study included 148 preoperative biopsies from primary rectal cancers and 153 surgically resected primary tumours, among them, 118 cases had both biopsy and surgical specimens from the same patient. All the endoscopic biopsies were taken by the surgeons, and qualified for a clinical diagnosis before radiotherapy (otherwise a biopsy was taken again for a diagnosis). All the patients had locally resectable rectal adenocarcinoma. The patients were from the southeast Swedish Health Care region, 
Table I. Characteristics of patients and tumours.

\begin{tabular}{|c|c|c|}
\hline Characteristics & $\begin{array}{l}\text { Non-radiotherapy } \\
(\%)\end{array}$ & $\begin{array}{c}\text { Radiotherapy } \\
(\%)\end{array}$ \\
\hline \multicolumn{3}{|l|}{ Gender } \\
\hline Male & $46(56.8)$ & $42(58.3)$ \\
\hline Female & $35(43.2)$ & $30(41.7)$ \\
\hline \multicolumn{3}{|l|}{ Age (years) } \\
\hline$\leq 66$ & $29(35.8)$ & $28(38.9)$ \\
\hline$>66$ & $52(64.2)$ & $44(61.1)$ \\
\hline \multicolumn{3}{|l|}{ Dukes' stage } \\
\hline A & $22(27.2)$ & $21(29.2)$ \\
\hline $\mathrm{B}$ & $22(27.2)$ & $24(33.3)$ \\
\hline $\mathrm{C}$ & $34(41.9)$ & $19(26.4)$ \\
\hline $\mathrm{D}$ & $3(3.7)$ & $8(11.1)$ \\
\hline \multicolumn{3}{|l|}{ Differentiation } \\
\hline Good & $2(2.5)$ & $2(2.8)$ \\
\hline Moderate & $65(80.2)$ & $54(75.0)$ \\
\hline Poor & $14(17.3)$ & $16(22.2)$ \\
\hline \multicolumn{3}{|l|}{ Number of tumours } \\
\hline Single & $75(92.6)$ & $64(88.9)$ \\
\hline Multiple $^{\mathrm{a}}$ & $5(6.2)$ & $7(9.7)$ \\
\hline Unknown & $1(1.2)$ & $1(1.4)$ \\
\hline \multicolumn{3}{|l|}{ Surgical type } \\
\hline Rectal amputation & $44(54.3)$ & $30(41.7)$ \\
\hline Abdominoperineal & $37(45.7)$ & $42(58.3)$ \\
\hline \multicolumn{3}{|l|}{ Resection margin } \\
\hline Tumour free & $78(96.3)$ & $67(93.1)$ \\
\hline Tumour & $3(3.7)$ & $5(6.9)$ \\
\hline \multicolumn{3}{|l|}{ To anal verge $(\mathrm{cm})$} \\
\hline Mean & 7.3 & 8.3 \\
\hline
\end{tabular}

${ }^{a}$ Other colorectal cancer and/or other type of tumours before the present rectal cancer.

and participated in a preoperative Swedish rectal cancer trial between 1987-1990 (10). Of the patients, 81 underwent tumour resection alone and 72 underwent preoperative RT before surgery. The required informed consent was given by all participants. Radiotherapy was given with 25 Gy in 5 fractions during a median of 6 days (range, 5-12 days). Surgery was then performed in a median of 3 days (range, 113 days) after radiotherapy. None of the patients received chemotherapy before surgery. The mean age of the patients was 66 years (range, 36-85 years) and the median follow-up was 86 months (range, 0-193 months). Other characteristics of the patients and tumours are presented in Table I.

Apoptotic cells were detected by the terminal deoxynucleotidy transferase-mediated dUTP-biotin nick end-labelling (TUNEL) assay (11), and the expressions of p53 (12) and Cox-2 (13) were determined by immunohistochemistry, the data were taken from previous studies performed at our laboratory. The percentage of apoptotic cells was determined by counting $\sim 1000$ tumour cells in 140 tumours, of which 68
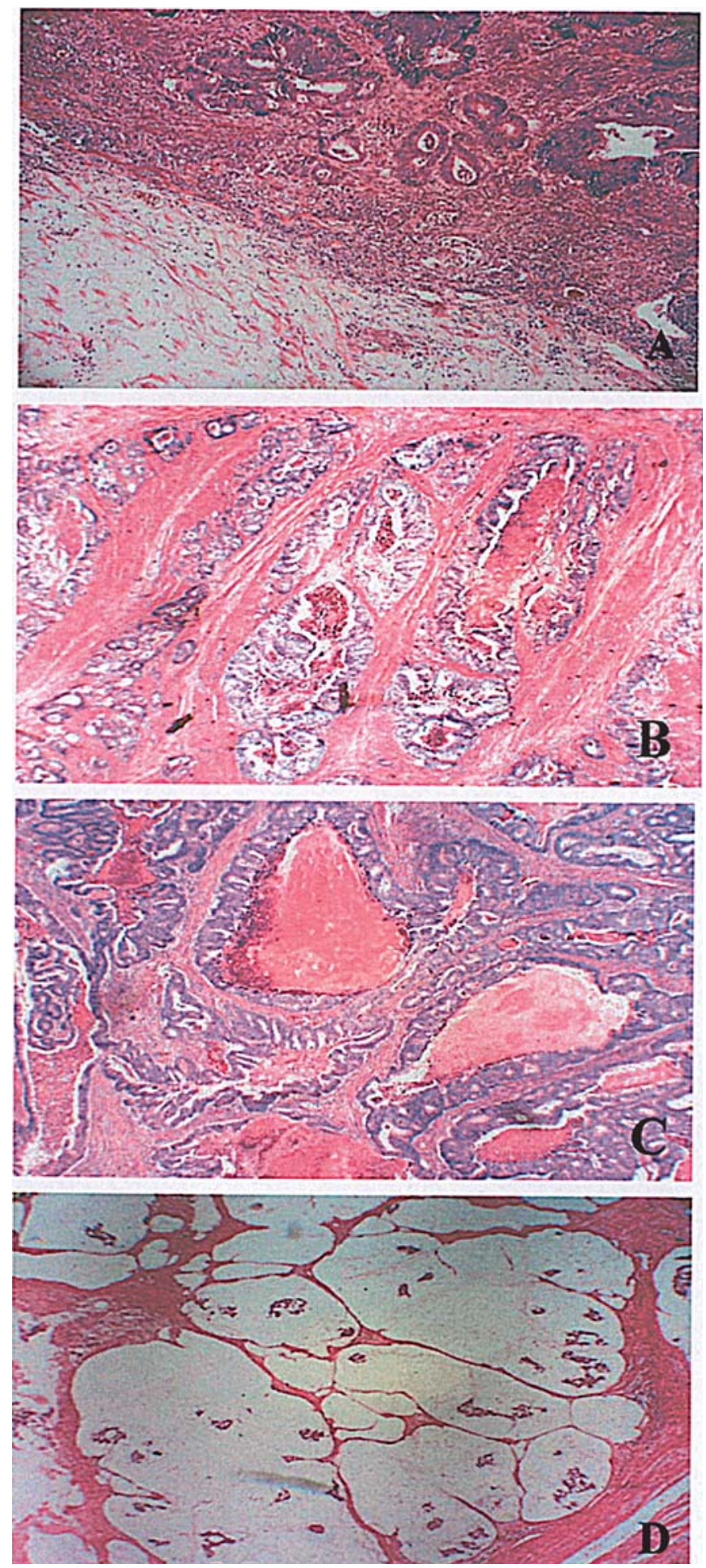

Figure 1. Histopathological parameters in rectal cancers. (A) Inflammatory infiltration at the invasive margin and in the inner area of the tumour. (B) Fibrosis surrounding tumour cells. (C) Necrosis. (D) Mucinous content in the tumour.

were negative and 72 were positive for apoptotic cells. p53 expression was examined in 147 cases, of which 116 were negative and 31 were positive. Of the 133 tumours with Cox-2 data, 63 had negative and 70 positive staining.

Methods. Paraffin-embedded 5- $\mu \mathrm{m}$ sections from surgical specimens and biopsies were routinely stained with hematoxylin and taken from Department of Pathology in 
Table II. Histopathological parameters, scores, subclasses and number of cases.

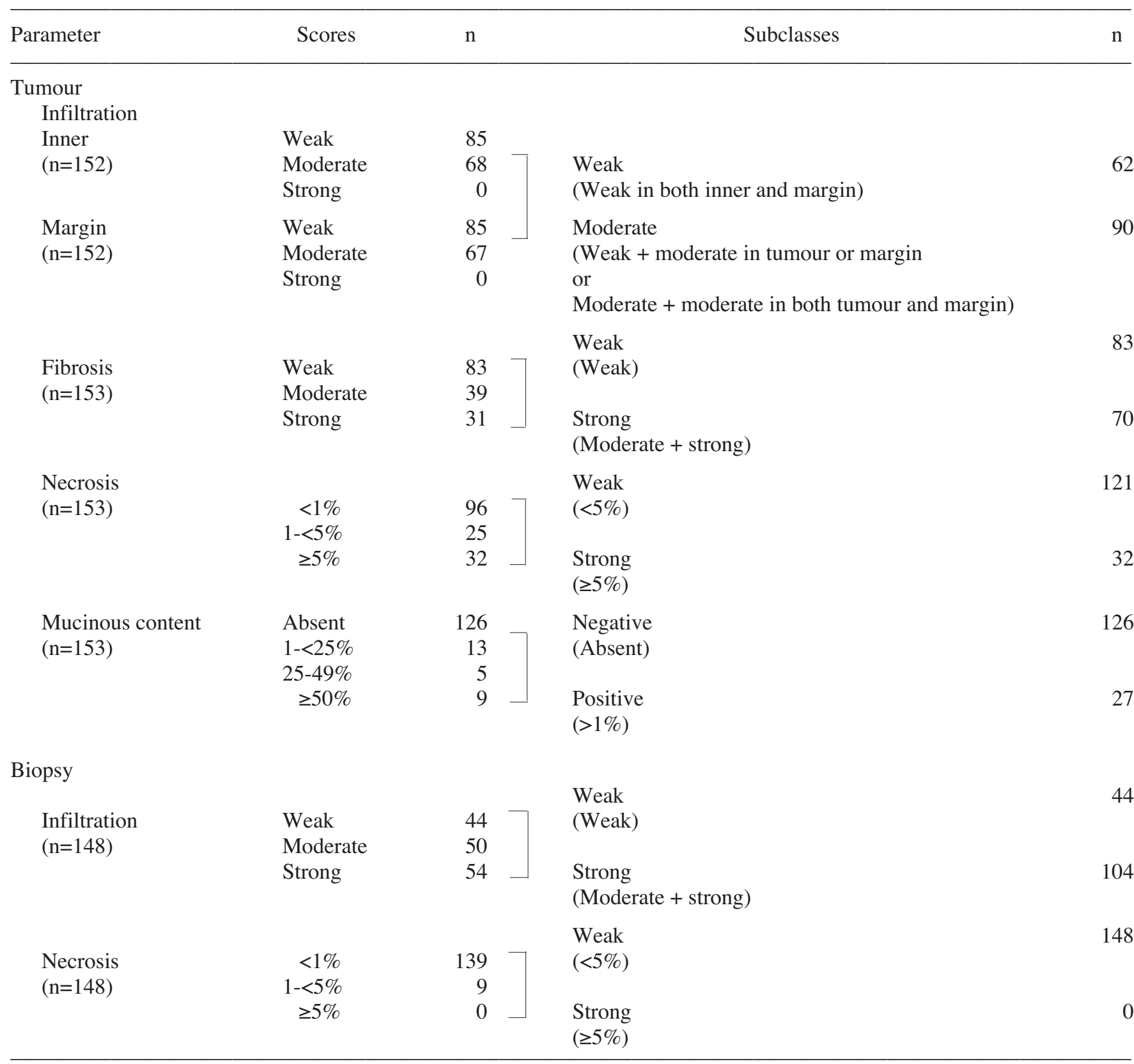

southeast Swedish Health Care region. In the surgical specimens, the following parameters were examined: i) inflammatory infiltration in the inner tumour and at the invasive margin of the tumour, ii) fibrosis, iii) necrosis, and iv) mucinous content. In biopsies, only inflammatory infiltration in the inner tumour and necrosis were evaluated, while inflammatory infiltration at the invasive margin of the tumour, fibrosis and mucinous content were not available due to small tumour areas. Two authors (A.K and X-F.S, pathologist) independently read the slides in a blinded fashion without any knowledge of the clinicopathological and biological information. The parameters were determined in 10-20 areas (depending on the size of the section) at $\mathrm{x} 400$ magnification. For each tumour/biopsy, 1-5 sections were analysed, and a mean score was reached. In the cases with discrepant results in the staining score, a consensus score was reached after re-examination. In the surgical specimen, no statistical difference was found when comparing the infiltration in the inner tumour with that at the invasive margin $(p=0.88)$. Therefore, for further analyses, the scores of the infiltration in both fields were combined (one section was excluded due to an invisible tumour margin). Table II presents the four parameters, scores, subclasses and case numbers in the analysis.

Statistics. The McNemar method was used to test the differences of histopathological parameters between the biopsies and tumours. The Chi-square method was used to test the relationships between the histopathological parameters and clinicopathologic/biological factors. Cox's proportional hazard model was used to estimate the relationship between the histopathological parameters and survival, including both univariate and multivariate analyses. Survival curves were computed according to the Kaplan- 

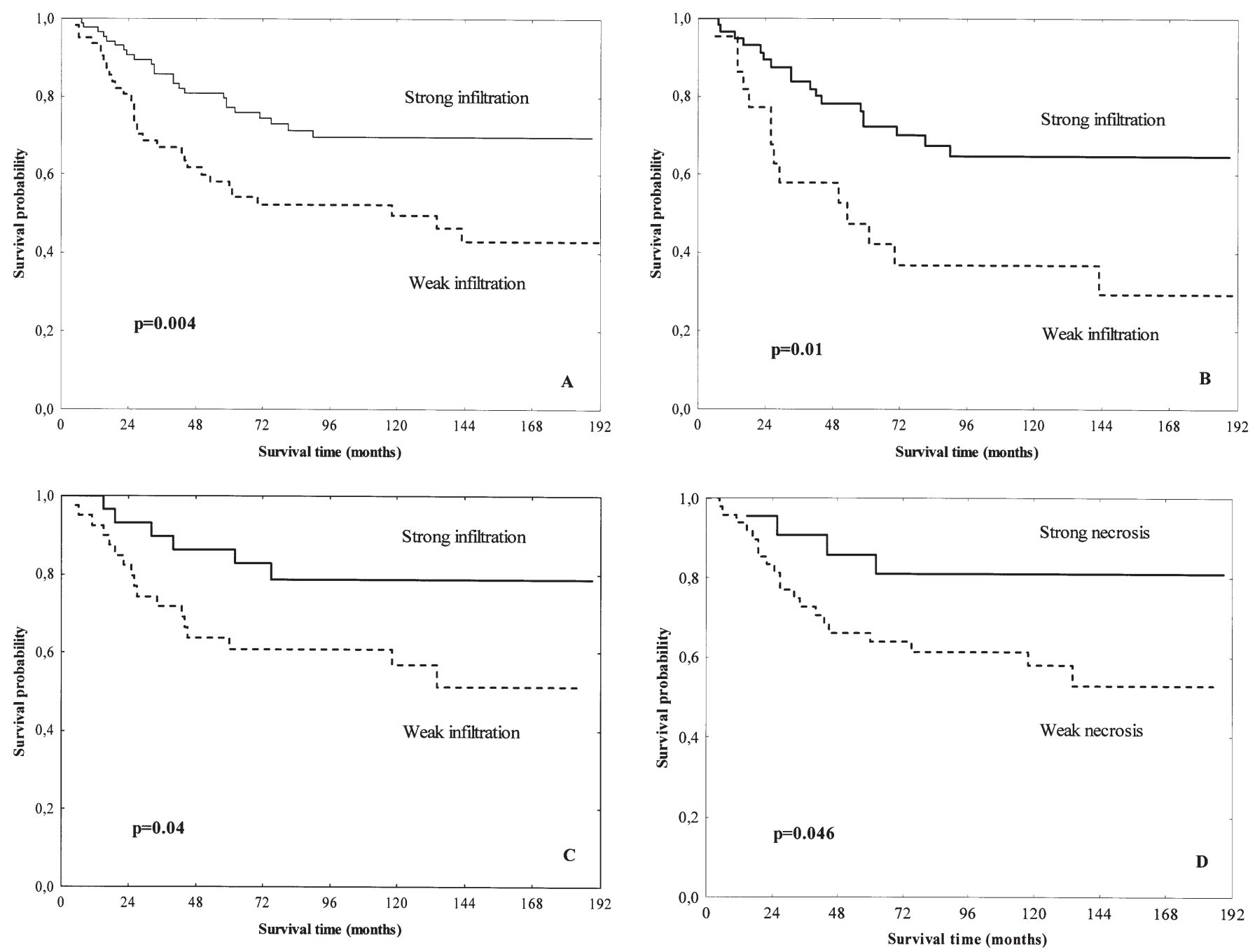

Figure 2. (A) The relationship between inflammatory infiltration and survival in the entire group of patients. (B) The relationship between inflammatory infiltration and survival in the subgroups of patients without RT. (C) The relationship between inflammatory infiltration and survival in the subgroups of patients with RT. (D) Necrosis in relation to survival in rectal cancer patients with RT.

Meier method. Tests were two-sided, and $\mathrm{p}<0.05$ was considered statistically significant.

\section{Results}

Histopathological parameters. In the surgical specimens, we examined inflammatory infiltration, fibrosis, necrosis and mucinous content (Fig. 1). A higher grade of infiltration was associated with more favourable survival compared to weak infiltration ( $\mathrm{p}=0.004$, Fig. $2 \mathrm{~A}$ ). Even in a multivariate analysis, the significance still remained, independent of gender, age, Dukes' stage, grade of differentiation, necrosis and fibrosis ( $\mathrm{p}=0.01$, Table III). Compared with weak infiltration, higher grade of the infiltration was more related to a decreased rate of distant recurrence $(\mathrm{p}=0.005)$, non-mucinous carcinoma $(\mathrm{p}=0.03)$ and younger patients $(<66$ years old, $\mathrm{p}=0.01$, data not shown).

In the biopsies, we examined only inflammatory infiltration and necrosis, and found that strong infiltration was related to a decreased rate of distant recurrence compared to weak infiltration (34\% of 104 cases vs $57 \%$ of $44, \mathrm{p}=0.009$ ).
These histopathological parameters (inflammatory infiltration, fibrosis, necrosis and mucinous content) were not related to other clinicopathological variables including gender, Dukes' stage, growth pattern, local recurrence, number of tumours, and complications ( $\mathrm{p}>0.05$ ).

Histopathological parameters in relation to radiotherapy. In the non-RT group, a higher grade of infiltration was related to favourable survival ( $p=0.01$, Fig. $2 B$ ), a lower rate of distant recurrence $(p=0.007)$ and younger age $(p=0.04)$. Tumours with strong necrosis had a higher rate of distant recurrence $(\mathrm{p}=0.04)$. Strong fibrosis was related to better (good + moderate) differentiated tumours $(\mathrm{p}=0.02)$.

In the RT group, both the higher grade of infiltration ( $p=0.04$, Fig. $2 \mathrm{C})$ and strong necrosis ( $\mathrm{p}=0.046$, Fig. 2D) were related to favourable survival.

Compared to tumours without RT, tumours treated with RT showed a decreased infiltration ( $\mathrm{p}=0.0003$, Fig. 3 ). In contrast, after RT, tumours had significantly increased necrosis compared to tumours without RT ( $\mathrm{p}=0.006$, Fig. 4).

We did not perform multivariate analyses in the subgroups due to the small number of cases. 
Table III. Multivariate analysis of inflammatory infiltration, gender, age, Dukes' stage, grade of differentiation, necrosis and fibrosis in relation to survival in rectal cancer patients.

\begin{tabular}{|c|c|c|c|c|}
\hline $\begin{array}{l}\text { Variable } \\
\text { Category }\end{array}$ & No. & $\begin{array}{l}\text { Cancer death } \\
\text { Rate ratio }\end{array}$ & $\begin{array}{l}95 \% \\
\mathrm{CI}\end{array}$ & P-value \\
\hline \multicolumn{5}{|l|}{ Infiltration } \\
\hline Weak & 60 & 1.0 & - & 0.01 \\
\hline Moderate & 87 & 0.4 & $0.2-0.8$ & \\
\hline Gender & & & & 0.01 \\
\hline Male & 87 & 1.0 & - & \\
\hline Female & 60 & 0.5 & $0.3-0.9$ & \\
\hline Age (years) & & & & 0.04 \\
\hline$\leq 66$ & 54 & 1.0 & - & \\
\hline$>66$ & 93 & 1.9 & $1.1-3.6$ & \\
\hline Dukes' stage & & & & $<0.0001$ \\
\hline A & 42 & 1.0 & - & \\
\hline B & 44 & 2.6 & $0.6-9.7$ & \\
\hline $\mathrm{C}$ & 51 & 13.2 & $4.2-43.6$ & \\
\hline $\mathrm{D}$ & 10 & 33.8 & 8.4-130.6 & \\
\hline Differentiation & & & & 0.74 \\
\hline Better & 112 & 1.0 & - & \\
\hline Worse & 35 & 1.1 & $0.6-1.9$ & \\
\hline Necrosis & & & & 0.59 \\
\hline Weak & 91 & 1.0 & - & \\
\hline Strong & 56 & 1.2 & $0.7-2.2$ & \\
\hline Fibrosis & & & & 0.74 \\
\hline Weak & 78 & 1.0 & - & \\
\hline Strong & 69 & 0.9 & $0.5-1.6$ & \\
\hline
\end{tabular}

Histopathological parameters in relation to biological factors. We examined the relationships of the histopathological parameters with the biological factors including p53, Cox-2 and apoptosis based on RT. In tumours with negative p53 expression, tumours with RT, compared to tumours without RT, tended to have more necrosis ( $95 \%$ of 22 cases vs $77 \%$ of $47, \mathrm{p}=0.054$ ) and fibrosis (93\% of 28 cases vs $76 \%$ of $41, \mathrm{p}=0.06)$. Necrosis was positively related to Cox -2 expression in the whole group $(\mathrm{p}=0.007)$, in the non-RT $(\mathrm{p}=0.04)$ and the RT group $(\mathrm{p}=0.01)$. These histopathological parameters were not related to apopotosis $(\mathrm{p}>0.05$, data not shown).

\section{Discussion}

Our present study showed that inflammatory infiltration was a prognostic factor in the whole group of patients with rectal cancer as well as in the subgroups of patients with or without RT. In the whole group the prognostic significance still

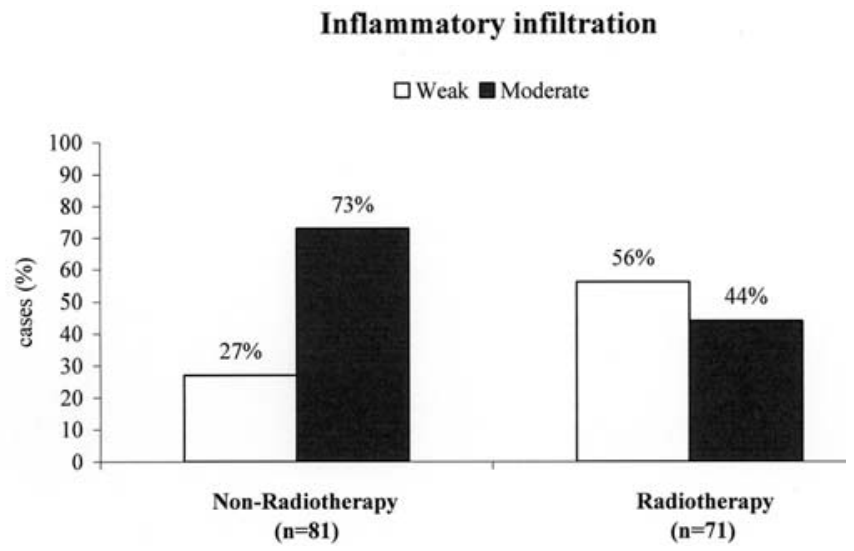

Figure 3. Inflammatory infiltration in rectal cancer in relation to RT.

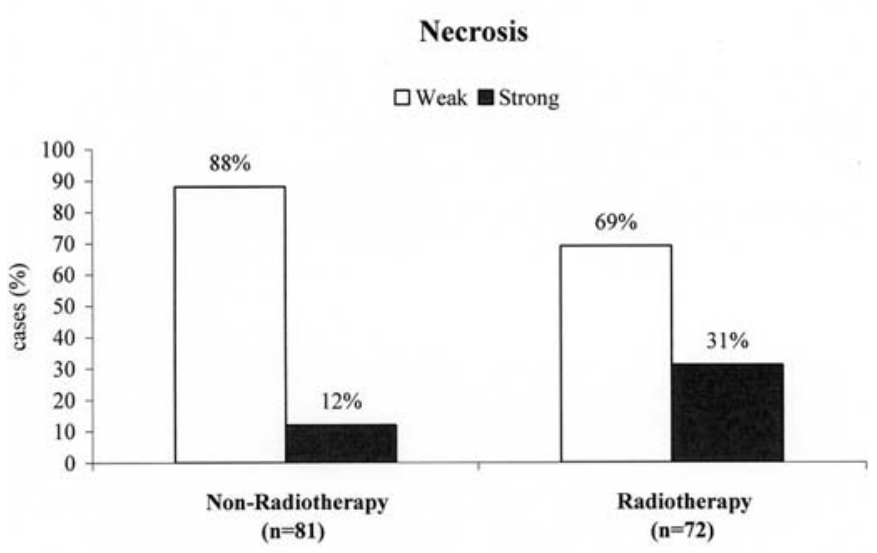

Figure 4. Necrosis in rectal cancer in relation to RT.

remained even after adjustment for gender, age, Dukes' stage, grade of differentiation, necrosis, and fibrosis. Multivariate analysis was not performed in the subgroups due to the small number of cases. The presence of inflammatory infiltrate was also correlated to a decreased rate of distant recurrence in the whole group of patients and in the non-RT group but not in the RT group. Nagtegaal et al (1) demonstrated an association between strong inflammatory infiltration and a decreased distant recurrence and favourable survival in rectal cancer patients who participated in a trial of preoperative RT, however, they did not identify this association in the subgroups of patients with or without RT. Klintrup et al (14) showed that extensive inflammatory infiltration at the invasive margin was related to favourable survival in patients with Dukes' stage A and B colorectal cancer without RT or chemotherapy. A previous study performed at our laboratory showed a positive correlation between inflammatory infiltration and survival in colorectal cancer patients, the majority of whom had no adjuvant treatments (out of 301 patients, 12 received RT before surgery and 3 received chemotherapy) (3). The underlying mechanism of infiltration in relation to prognosis may be caused by activated B-cells that produce antibodies against tumour antigens, an increased amount of activated macrophages that release interleukin-4 (IL-4) and tumour necrosis factor- $\alpha(\mathrm{TNF}-\alpha)$, induction of 
cytotoxic T-lymphocytes by specific antigens presented on MHC class I receptors, activation of NK cells by an antigenantibody complex and a cascade reaction of complement, which all finally leads to lysis of the tumour cell $(4,15)$. Taken together, these findings indicate that inflammatory infiltration is a good prognostic sign in colon and/or rectal cancer patients with or without preoperative RT or chemotherapy. Our present study showed that younger patients without RT had more inflammatory infiltration around the tumour cells suggesting that younger patients had a better immunological response than older patients.

We observed that infiltration was decreased after RT, which was in line with a study of rectal cancers (16). RT was suggested to stimulate tumour cells to produce TGF- 31 (17), which in turn inhibits the immune function of $\mathrm{CD}^{+}$and CD4 ${ }^{+} \mathrm{T}$-lymphocytes in normal tissue from jejunum (18). It is also shown that a T-cell specific blockade of TGF- $\beta$ induced a immune response resulting in the eradication of tumours in mice challenged with thymoma and melanoma cancer cell lines (19).

Tumour necrosis is caused by a rapid tumour growth without sufficient blood supply, which leads to ischemia and necrosis of the tumour $(3,8)$. Previous studies demonstrated that necrosis was associated with a poor clinical outcome in patients with colorectal cancer $(3,8,9)$. In the present study, we did not directly find an association between necrosis and survival in the non-RT and in the whole group, but we did find that necrosis was related to favourable survival in the RT group, where necrosis was increased in tumours with RT compared to tumours without RT. Thus, in our cases there were two ways to initiate necrosis, by rapid tumour growth and by irradiation.

Our previous study on the same series of cases showed that preoperative RT reduced the local recurrence rate in $\mathrm{p} 53$ negative tumours but there was no such evidence in p53positive tumours (12). Interestingly, in the present study, we found a trend that after RT both necrosis and fibrosis were increased in p53-negative tumours. Thus, p53-negative tumours that had a better response to RT may be via necrosis and fibrosis induced by RT. It has been demonstrated that necrosis is initiated by the destruction of capillaries by RT that leads to oxygen deficit in the tissue and an initiation of necrosis in the tumour (20). We propose that this reaction, to some extent, may be through a p53 pathway. Fibrosis consists of dense connective tissue, and has an antitumour effect by limiting the progression of tumour cells (5). We and others have found a relationship between extensive fibrosis and favourable survival and better differentiation in rectal cancer patients without preoperative RT or chemotherapy (5). RT is suggested to stimulate the production of TGF- $\beta$, which in turn activates myofibroblasts to produce fibrosis (17), and this process might also be related to p53 expression.

In recent years, the importance of Cox- 2 has been shown in the development and progression of colorectal cancers. However, few studies have investigated the relationship between Cox-2 and necrosis. Only an in vitro study showed a dramatic induction of Cox-2 expression around necrotic cells in fibroblast cell lines after cell-cell contact (21). In this study, we first observed a positive relationship between Cox-2 expression and necrosis in tumours both with and without
RT in rectal cancer patients. Coagulative necrosis is caused by ischemia that leads to irreversible exogenous injury of the cell, macrophages are activated and begin to migrate towards this area via chemotactic agents released by the tissue damage, and the activated macrophages then release tumour necrosis factor- $\alpha$ (TNF- $\alpha)$; this cytokine was shown to upregulate Cox-2 in normal and malignant prostate cells (22). We suggest that the increased level of Cox-2 around necrotic cells stimulated the inflammatory process that was needed to remove the dead material from the tissue regardless of RT.

In summary, inflammatory infiltration was a prognostic factor in rectal cancer patients regardless of preoperative RT although the radiation may depress the inflammatory infiltration. The increased necrosis and fibrosis in p53-negative tumour cells after RT, and the necrosis and fibrosis effect on clinical outcome are a subject for further biological and clinical investigations. This issue could be important in selecting the best suited patients for preoperative RT in the future.

\section{Acknowledgements}

The authors thank Professor Bo Nordenskjöld and Dr Kerstin Nordenskjöld for their support. The study was supported by grants from the Swedish Cancer Foundation and the Health Research Council in the southeast of Sweden.

\section{References}

1. Nagtegaal ID, Marijnen C, Kranenbarg EK, et al: Local and distant recurrences in rectal cancer patients are predicted by the nonspecific immune response; specific immune response has only a systemic effect - a histopathological and immunohistochemical study. BMC Cancer 1: 7, 2001.

2. Shia J, Guillem JG, Moore HG, et al: Patterns of morphologic alteration in residual rectal carcinoma following preoperative chemoradiation and their association with long-term outcome. Am J Surg Pathol 28: 215-223, 2004.

3. Gao J-F, Arbman G, Wadhra T, Zhang H and Sun X-F: The relationships of tumour inflammatory infiltration and necrosis with microsatellite instability in colorectal cancers. World J Gastroenterol 11: 2179-2183, 2005.

4. Arancia G, Malorni W and Donelli G: Cellular mechanisms of lymphocyte-mediated lysis of tumor cells. Ann Ist Super Sanita 26: 369-384, 1990.

5. Ueno H, Jones AM, Wilkinson KH, Jass JR and Talbot IC: Histologic categorisation of fibrotic cancer stroma in advanced rectal cancer. Gut 53: 581-586, 2004.

6. Adachi Y, Mori M, Kuroiwa S, Sugimachi K and Enjoji M: Histopathologic evaluation of survival time in patients with colorectal carcinoma. J Surg Oncol 42: 219-224, 1989.

7. Akino F, Mitomi H, Nakamura T, Ohtani Y, Ichinoe M and Okayasu I: High apoptotic activity and low epithelial cell proliferation with underexpression of $\mathrm{p} 21^{\mathrm{WAF} 1 / \mathrm{CIP} 1}$ and $\mathrm{p} 27^{\mathrm{Kip} 1}$ of mucinous carcinomas of the colorectum. Am J Clin Pathol 117: 908-915, 2002.

8. Swinson D, Jones L, Richardson D, Cox G, Edwards J and O'Byrne K: Tumour necrosis is an independent prognostic marker in non-small cell lung cancer: correlation with biological variables. Lung Cancer 37: 235-240, 2002.

9. Lammering G, Taher MM, Gruenagel HH, Borchard F and Porschen R: Alterations in DNA ploidy status and cell proliferation induced by preoperative radiotherapy is a prognostic factor in rectal cancer. Clin Cancer Res 6: 3215-3221, 2000.

10. Swedish Rectal Cancer Trial: Improved survival with preoperative radiotherapy in resectable cancer. N Engl J Med 336: 980-987, 1997.

11. Adell GC, Zang H, Evertsson S, Sun XF, Stål OH and Nordenskjöld BA: Apoptosis in rectal cancer: Prognosis and recurrence after preoperative radiotherapy. Cancer 91: 1870-1875, 2001. 
12. Adell GC, Sun X-F, Stål O, Klintenberg C, Sjödahl R and Nordenskjöld B: p53 status: An indicator for the effect of preoperative radiotherapy in rectal cancer. Radiother Oncol 51: 169-174, 1999.

13. Pachkoria K, Zang H, Adell G, Jarlsfelt I and Sun XF: Significance of COX-2 expression in rectal cancers with or without radiotherapy. Int J Radiat Oncol Biol Phys 63: 739-744, 2005.

14. Klintrup K, Mäkinen J, Kauppila S, et al: Inflammation and prognosis in colorectal cancer. Eur J Cancer 41: 2645-2654, 2005.

15. Barth R, Camp B, Martuscello T, Dain B and Memoli V: The cytokine microenviroment of human colon carcinoma: Lymphocyte expression of tumor necrosis factor- $\alpha$ and interleukin-4 predicts improved survival. Cancer 78: 1168-1178, 1998.

16. Nagtegaal ID, Marijnen CA, Kranenbarg EK, et al: Short-term preoperative radiotherapy interferes with the determination of pathological parameters in rectal cancer. J Pathol 197: 20-27, 2002.

17. Martin M, Lefaix J-L and Delanian S: TGF- $\beta 1$ and radiation fibrosis: A master switch and a specific therapeutic target? Int J Radiat Oncol Biol Phys 47: 277-290, 2000.
18. Ebert EC: Inhibitory effects of transforming growth factor-beta (TGF- $\beta$ ) on certain functions of intraepithelial lymphocytes. Clin Exp Immunol 115: 415-420, 1999.

19. Gorelik L and Flavell R: Immune-mediated eradication of tumours through the blockade of transforming growth factor- $\beta$ signaling in T cells. Nat Med 7: 1118-1122, 2001.

20. Vujaskovic Z, Mitchell S, Anscher M, et al: Radiation-induced hypoxia may perpetuate late normal tissue injury. Int $\mathrm{J}$ Radiat Oncol Biol Phys 50: 851-855, 2001.

21. Bizik J, Kankuri E, Ristimäki A, Taieb A, Vapaatalo H, Lubitz W and Vaheri A: Cell-cell contacts trigger programmed necrosis and induce cyclooxygenase-2 expression. Cell Death Differ 11: 183-195, 2004.

22. Subbarayan V, Sabichi A, Llansa N, Lippman S and Menter D: Differential expression of cyclooxygenase- 2 and its regulation by tumor necrosis factor- $\alpha$ in normal and malignant prostate cells. Cancer Res 61: 2720-2726, 2001. 